\title{
The Mental Capacity Act 2005
}

\author{
Darren Shickle
}

\begin{abstract}
The Mental Capacity Act 2005 covers all decisions on personal welfare including financial matters, relating to people who temporarily or permanently lack mental capacity. This paper outlines the most important provisions of the Act and describes some of the implications for healthcare professionals. For example, the Act permits advance decisions to refuse healthcare; the appointment of a person to have a Lasting Power of Attorney to act on a person's behalf at some point in the future; the appointment of a court-appointed deputy to act on behalf of a person lacking mental capacity; and research involving people who lack mental capacity in specific circumstances. The Court of Protection will now have a role in resolving difficult ethical problems in clinical cases.
\end{abstract}

KEY WORDS: mental capacity, Mental Capacity Act 2005

\section{Background}

The Mental Capacity Act 2005 received Royal Assent on 7 April 2005. The Act applies to England, but provides powers for the Welsh Assembly to introduce similar regulations in Wales. There is separate legislation in relation to Scotland. ${ }^{1}$ The Act follows on from the Government's 1999 Policy Statement, Making decisions, ${ }^{2}$ and the Law Commission's recommendations in 1995 for a statutory framework for decisionmaking for adults who lack mental capacity. ${ }^{3}$ The Mental Incapacity Bill, as it was initially called, underwent pre-legislative scrutiny by a Joint Committee of Parliament. The Scrutiny Committee published their report on the draft Mental Incapacity Bill in November 2003. ${ }^{4}$ A draft Code of Practice ${ }^{5}$ was produced to accompany the passage of the Bill through Parliament, and this will need to be updated to take account of amendments made to the Bill.

\section{Main principles of the Bill}

The Act aims to provide consistently better protection and greater empowerment for vulnerable people. It is supportive and enabling when people are faced with the sensitive job of handling decisions - either when someone cannot decide something for themselves or there is a doubt about it. The Act aims to clarify a number of legal uncertainties as to when people can act on behalf of people who lack mental capacity; for example, in making healthcare decisions but also when it is permissible for a neighbour to use a person's money to shop on their behalf.

The Act is empowering because it states unequivocally that everyone should be treated as able to take all their own decisions until it is shown that they cannot (paragraph 1(2)). No one should just be labelled 'incapable': each decision should be considered individually. It emphasises and maximises people's autonomy and sets out clear guidelines for, and limits on, other people's role in decision making.

The principles stated at the outset of the Act (paragraphs 1(2-6)) are that:

- A person must be assumed to have capacity unless it is established that he or she lacks capacity.

- A person is not to be treated as being unable to make a decision unless all practicable steps to help him or her to do so have been taken without success.

- A person is not to be treated as unable to make a decision merely because he or she makes an unwise decision.

- An act done, or decision made, for or on behalf of a person who lacks capacity must be in his or her best interests.

- Before the act is done, or the decision made, regard must be had to whether the purpose for which it is needed can be effectively achieved in a way that is less restrictive of the person's rights and freedom of action.

The Act relates to anyone lacking mental capacity. It covers people with acute, temporary loss of mental capacity, eg during unconsciousness following a road traffic accident; people with learning difficulties who are capable of being involved in or even responsible for some decisions; as well as people in permanent vegetative state (PVS).

The Act introduces a new criminal offence of neglect that can be used against anyone who has illtreated or wilfully neglected a person who lacks capacity (paragraphs 44(1-3)).
Darren Shickle MD FFPHM, Professor of Public Health, Institute of Health Sciences and Public Health Research, University of Leeds 


\section{Defining mental incapacity}

A decision as to whether someone lacks mental capacity to make a specific decision is to be made on the balance of probabilities (paragraph 2(4)).

A person should be considered as being unable to make decisions for themselves (paragraph 3(1)) if they are unable:

- to understand the relevant information

- to retain that information for long enough necessary to make a decision

- to use or weigh that information as part of the decisionmaking process

- to communicate their decision.

Hitherto, defining someone as lacking mental capacity has been a medico-legal decision requiring specialist expertise. ${ }^{6}$ As the Act requires an assessment of mental capacity to be made in the context of every decision that must be taken, lay people will be expected to form judgements as to whether the person has the capacity to make a particular decision. The draft Code of Practice ${ }^{5}$ suggests that the following factors and situations might indicate the need for professional involvement (paragraph 3.37):

- the gravity of the decision or its consequences

- where the person concerned disputes a finding of incapacity

- where there is disagreement between family members, carers and/or professionals as to the person's capacity

- where the person concerned is expressing different views to different people

- where the person's capacity to make a particular decision may be subject to challenge, eg testamentary capacity to make a will

- where there may be legal consequences of a finding of capacity, eg settlement of damages for a personal injury claim

- the person concerned is repeatedly making decisions that put him/her at risk.

\section{Making decisions on behalf of a person lacking mental capacity}

A decision must be made in a person's best interests (paragraph 4(1.7)). When making such a decision, consideration must be given to:

- whether they will have sufficient capacity to make decisions on that subject in the future and if so what they are likely to want

- possible means of helping the person participate in the decision

- the person's past and present wishes, feelings, beliefs and values

- where practicable and appropriate, the views of relevant others eg carers, people given lasting power of attorney, court appointed deputies.

\section{Advance decisions refusing treatment}

A competent person may refuse treatments. They may also specify which treatments they would like withheld or withdrawn if they were to develop mental incapacity. The Common Law already allows them to do this, but the Act makes the operation of such advance refusals clearer.

According to the draft Code of Practice (paragraph 8.10), an advance decision to refuse treatment:

- may be written or made orally

- must specify the treatment that is to be refused (this can be in lay terms, as long as it is clear what is meant)

- may set out the circumstances in which the refusal will apply

- will only apply when the person lacks capacity to consent to the specified treatment.

If the patient has been able to predict precisely the circumstances that they are in, then advance decisions will be binding. Many of the critics of the Act, for example pro-life groups, wanted advance decisions to be advisory ie to give the doctors discretion to ignore them. There are concerns about the ability of patients to predict accurately how they would feel about their condition until they are actually faced by a particular clinical problem. Advance decisions will also not be binding if the doctor is in any doubt about the intentions of the patient, about whether the patient was competent at the time of writing the directive, or about its validity. For example, suicide notes will not be binding. Thus given these difficulties, doctors will need to interpret the wishes of the patient, with the advice of the patient's relatives.

\section{Key Points}

The Mental Capacity Act relates to anyone with mental incapacity whether it is temporary or longstanding

It acknowledges that people who have impaired mental capacity still have the ability to make some decisions, and efforts should be made to facilitate this wherever practicable

It also allows people currently with mental capacity to indicate their wishes if they were to develop mental incapacity in the future via Advance Decisions of Refusal, or to appoint people to make decisions on their behalf via a Lasting Power of Attorney

Many of its provisions were permitted previously under the Common Law but have now been clarified or made explicit

A draft Code of Practice was produced at the time that the Bill was being considered by Parliament. Further guidance is currently being produced. The Act may increase the workload of health professionals who have to respond to requests for help from patients drafting Advance Decisions of Refusal, or checking their validity. The extent to which the Act will help to resolve difficult ethical decisions, disagreement on the best interests of a patient, or disputes with/between relatives is unclear 
There may be workload implications for doctors, especially GPs, if many patients want advice on drawing up advance decisions. It is not clear whether the giving of advice when a patient is writing an advance decision is an expected part of the current role of doctors. This may depend on whether a patient is currently healthy or is asking for information about prognosis and treatment options in the future. Guidance is required on the legal standing of this advice. There is also concern about additional obligations on doctors to check whether a patient has made an advance decision, and if they have to check that it is valid. This responsibility may be particularly difficult to discharge in emergency situations when rapid decisions must be made.

The intention of the Act is to give people who lack mental capacity the same rights, as far as is practicable, as those who have mental capacity. Just as, at present, people with mental capacity cannot insist that they be given certain treatments, so they cannot stipulate that in the future, under an advance decision, the NHS must provide them with treatments that it does not routinely offer, eg based on cost effectiveness. Hence the Government has explicitly described them as 'advance decision of refusal' rather than 'advance directives or livings wills' as such documents are sometimes described.

\section{Lasting Power of Attorney (LPA)}

A Lasting Power of Attorney (LPA) is a new statutory form of power of attorney created by the Mental Capacity Act (paragraphs 9-14). The Act allows anyone who has capacity to specify one or more persons to take decisions on their behalf if they subsequently lose capacity. An LPA can deal with personal health and welfare matters and/or property and financial affairs, unlike previously when the remit of someone with Enduring Power of Attorney only covered property and financial affairs. A person acting under an LPA (the donee) can only do so if (paragraphs 11(1-5)):

- they reasonably believe that the person that they are acting for (the doner) lacks capacity required to make the decision

- they reasonably belive it is necessary to act in order to prevent harm to the doner

- the act is a proportionate response to the likelihood and seriousness of harm.

If the doner has given them permission to do so, the authority of the donee of the LPA can extend from giving or refusing consent to the carrying out or continuation of a healthcare. This can include life-sustaining treatments, if the LPA explicitly states so (paragraphs 11(7-8)).

\section{Court of Protection}

The Court of Protection will in future make decisions about the health and social well-being of people lacking mental capacity (paragraphs 45-53), whereas previously it only dealt with financial matters relating to such people. As a general rule, the Court's permission to hear a case must first be sought before an application can be made. A person who lacks, or who is alleged to lack, capacity - or someone acting on their behalf who has a lasting power of attorney or is a court-appointed deputy - does not need to seek permission before bringing an application to the Court. It is envisaged that the Court proceedings may be informal and be able to respond to emergencies and rapidly changing clinical circumstances. The mode of operation for this new role for the Court of Protection will be important. It is hoped that the mechanism for referring cases to the Court of Protection will be as simple and timely as possible, given that clinical decisions frequently have to be responsive to rapid changes in clinical circumstances.

\section{Court-appointed deputies}

Where the Court of Protection believes that there is a need for on-going decision-making powers for a person lacking capacity, it may appoint a deputy to act on their behalf (paragraphs 16-19). The Act places various restrictions on the powers of deputies, for example a deputy may not refuse consent to the carrying out or continuation of life-sustaining treatment (paragraphs 20(1-11)).

\section{The Public Guardian}

The Public Guardian will have responsibility for establishing and maintaining registers of Lasting Powers of Attorney and court-appointed deputies (paragraphs 57-58). The Public Guardian also has powers to monitor, if necessary, the actions of people acting under an LPA or as a court-appointed deputy via Court of Protection visitors (paragraph 61).

\section{Duty to seek advice in connection with serious medical treatment}

There was considerable debate as part of the pre-legislative scrutiny of the Draft Mental Incapacity Bill in relation to withholding of artificial nutrition and hydration (ANH). The Draft Bill attracted severe criticism from the pro-life lobby, who suggested that it would permit euthanasia by allowing the withholding or withdrawal of life-sustaining treatments - either because of an advance decision or because of a decision by the family, doctors and/or the courts that it was in the best interests of the patient to be allowed to die.

The Act does not change the expectation that controversial cases involving serious healthcare and treatment decisions will be brought before the Court of Protection. These would include:

- proposed withholding or withdrawal of ANH from patients in PVS

- proposed non-therapeutic sterilisation of a person lacking capacity to consent to this (eg for contraceptive purposes)

- other cases involving ethical dilemmas in untested areas, or where there are otherwise irresolvable conflicts between professionals, or between professionals and family members. 


\section{Research involving people lacking mental capacity}

Previously there was considerable uncertainty about the legality of conducting research in relation to diseases associated with mental incapacity. The Draft Mental Incapacity Bill did not contain any specific reference to research. It was felt that specific reference to research was unnecessary as the Bill included provisions for third parties to act in the best interests of someone with mental incapacity. Thus if participation in a research study was in someone's best interest, then a third party could lawfully give consent on his or her behalf. The Joint Committee on the Draft Mental Incapacity ${ }^{4}$ concluded that a clause should be included in the Bill to enable strictly controlled medical research to explore the causes and consequences of mental incapacity and to develop effective treatment for such conditions.

Research forming part of clinical trials of medicinal products for human use is not included in the Mental Capacity Bill, but it is covered by the Medicines for Human Use (Clinical Trials) Regulations $2004^{7}$ that implement the European Clinical Trials Directive. ${ }^{8}$ These regulations permit research involving people lacking mental capacity in defined circumstances, with specific protections in place. A third party may give consent on their behalf if they are a relative, a health professional responsible for their care if they are independent of the clinical trial, or a person independent of the trial who has been nominated by the organisation to decide on whether it is in the interests of the patient to participate in the trial.

The Mental Capacity Act itself permits other intrusive research approved by an appropriate body (likely to be an accredited research ethics committee) to be carried out on a person lacking mental capacity (paragraphs 30(1-4)). Intrusive research is defined in terms of whether consent would be required of a person who is mentally competent.

The research must be connected with a condition which is causing or contributing to the mental impairment, or its treatment (paragraphs $31(2-3)$ ). The research may also only be performed if there are reasonable grounds for believing that the research would not be effective if it were only conducted on people with mental capacity who would be able to consent in their own right (paragraph 31(4)). It is clear that the intention is not to abuse the patient by performing research where they do not have the disease themselves, eg using the patient as a subject control, or where the patient also has a disease that is incidental to their cause of the mental incapacity, as in the latter situation the research could be conducted on patients capable of being asked for consent.

The Mental Capacity Act has 'best interests' of the person with mental incapacity at its core. However, the 'best interests' test is not used within the provisions on research. It is impossible to guarantee that even well evaluated treatments will produce benefits and no risk, so it is only feasible to consider risks in terms of balance of probability. There is likely to be even more uncertainty around anticipated benefits and risks in relation to interventions in the research context.

A significant omission in the Act, however, is a statement that the interests of the patient always prevail over those of science and society, such as can be found in the European Clinical Trials Directive $^{8}$ or the World Medical Association Declaration of Helsinki. ${ }^{9}$ Instead, the Mental Capacity Act requires (paragraph 31(5)) that the research must either:

- have the potential for benefiting the patient without imposing a burden, eg risks of side effects, that is disproportionate to these potential benefits; or

- be intended to provide knowledge of the causes or treatment of, or of the care of persons affected by, the same or similar condition.

This approach of balancing probabilities of benefits and risks, rather than assessing what is in the 'best interests', is in keeping with the Adults with Incapacity (Scotland) Act $2000^{1}$ which uses the word 'likely', while the European Clinical Trials Directive ${ }^{8}$ talks of expected benefits and risks. The potential to involve people who lack mental capacity where benefits are only likely to accrue to similarly situated patients is, however, a significant aspect of the Act, although in these circumstances the risks to the research participant must be likely to be negligible, and there should be no significant intrusion into their privacy or be unduly invasive or restrictive.

As with the Medicines for Human Use (Clinical Trials) Regulations 2004, ${ }^{7}$ there must be consultation with a relative, carer or other nominated person who is independent of the research to advise on whether the person lacking mental capacity should be included within the research, and what would have been the likely wishes of the patient if they had been able to consent for themselves (paragraphs 32(16)). However, the Act does not refer to these third parties as being able to give consent on behalf of the patient. But if this independent person thinks that the patient would not want to be included or continue to participate in the research, then the researcher must respect this opinion, unless they obtain a court order permitting them to include the patient in the research.

Patients lacking mental capacity may be enrolled in research in emergency situations, if the researchers obtain the agreement of a registered medical practitioner who is not concerned in the patient's care or, where time does not permit even the opportunity to seek such agreement, there has been prior approval by an appropriate body (eg an accredited research ethics committee) (paragraphs 32(8-10)).

\section{Conclusion}

On balance, the Mental Capacity Act is to be welcomed. It provides sensible protections for vulnerable patients as well as additional clarification on what may or may not be done when acting on behalf of people lacking mental capacity - over and above what was possible previously under Common Law. However, there may be implications for doctors in terms of workload. As with all new legislation, the NHS will need to consider how it will address the training needs of doctors on the implications of the Mental Capacity Act and its implementation. 


\section{References}

1 Adults with Incapacity (Scotland) Act 2000. www.opsi.gov.uk/legislation/scotland/acts2000/20000004.htm. Accessed 19 January 2006.

2 Lord Chancellor's Department. Making decisions: the Government's proposals for making decisions on behalf of mentally incapacitated adults. London: Stationery Office, 1999.

3 Law Commission. Mental incapacity, Report No 231. London: HMSO, 1995.

4 House of Lords and House of Commons Joint Committee on the Draft Mental Incapacity Bill. Draft Mental Incapacity Bill. The Joint Committee's First Report, Session 2002-03, HL Paper 189-I HC 1083-I. London: Stationery Office, 2003.

www.publications.parliament.uk/pa/jt/jtdmi.htm. Accessed 19 January 2006.

5 Department of Constitutional Affairs. Mental Capacity Bill: draft code of practice. London: Department of Constitutional Affairs, 2005. www.dca.gov.uk/menincap/mcbdraftcode.pdf. Accessed 19 January 2006.
6 Hotopf M. The assessment of mental capacity. Clin Med 2005;5:580-4.

7 The Medicines for Human Use (Clinical Trials) Regulations 2004 Statutory Instrument 2004 No. 1031. London: Stationery Office, 2004 www.opsi.gov.uk/si/si2004/20041031.htm. Accessed 19 January 2006.

8 Directive 2001/20/EC on the approximation of the laws, regulations and administrative provisions of the Member States relating to the implementation of good clinical practice in the conduct of clinical trials on medicinal products for human use.

http://europa.eu.int/eur-lex/pri/en/oj/dat/2001/1_121/1_1212001050 1en00340044.pdf. Accessed 19 January 2006.

9 World Medical Association. World Medical Association Declaration of Helsinki: ethical principles for medical research involving human subjects. Last amended Edinburgh, October 2000.

www.wma.net/e/policy/b3.htm. Accessed19 January 2006. 